\title{
Ortaokul Öğrencilerinin Harita Okuryazarlık Becerisi Yeterlilikleri Üzerine Bir
}

\author{
Çalışma* \\ Erhan GÖRMEZ**
}

Öz: Harita okuryazarlığı becerisi çocukluk döneminde kazanılması gereken ve etkili kullanımına bağlı olarak yaşamı oldukça kolaylaştıran önemli bir beceridir. Bu becerinin çocuklara kazandırılmasında önemli derslerden biri de sosyal bilgilerdir. Çalışmanın amacı da sosyal bilgiler dersini dört yıl almış ortaokul 8. sınıf öğrencilerinin harita okuryazarlık becerisi konusundaki yeterliliklerini ortaya koymaktır. Araştırmanın örneklemini 2018-2019 eğitim öğretim döneminde Van il merkezinde bulunan dört farklı ortaokulda öğrenim gören toplam 90 8. sınıf öğrencisi oluşturmaktadır. Araştırmada veriler açık uçlu anket aracılığıyla toplanmıştır. Nicel bir yaklaşımın benimsendiği çalışmada veriler SPSS 21.0 paket programı kullanılarak çözümlenmiştir. Verilerin analizi için frekans ve yüzdelik değerlere bakılmıştır. Araştırma sonucunda ulaşılan bulgular incelendiğinde; öğrencilerin harita kavramı, haritada bulunması gereken kriterler, harita türleri, haritada kullanılan renklerin anlamları, haritadaki sembollerin anlamları ve yeryüzü kavramı gibi konularda yeterli bilgi düzeyine sahip olmadıkları; enlem ve boylam kavramlarını çoğunlukla "paralel ve meridyen" kavramlarıyla karıştırdıkları; Türkiye'nin koordinatlarını genelde karıştırdıkları ve verilen koordinatlara göre yer tespiti yapma konusunda tam bir yeterliliğe sahip olmadıkları tespit edilmiştir.

Anahtar Kelimeler: Harita okuryazarlığı, Sosyal bilgiler, Ortaokul, Öğrenci

\section{A Study on Map Literacy Skill Competences of Secondary School Students}

Abstract: Map literacy is an important skill that should be acquired in childhood and makes life easier if it is used effectively. One of the important course for teaching this skill to children is social studies. The aim of the study is to reveal the competences of 8th grade middle school students, who took the social studies course in four years, on map literacy skills. The sample of the research consists of 90 8th grade students studying at four different secondary schools in

\footnotetext{
*** $\mathrm{Bu}$ araştırma için Van Yüzüncü Yıl Üniversitesi Sosyal ve Beşeri Bilimleri Etik Kurulu Başkanlığında (07/07/2020 tarih ve 604.01.02-E.44328 sayısı) etik izin alınmıştır.

**Doç. Dr. Van Yüzüncü Y1l Üniversitesi, Eğitim Fakültesi, Türkçe ve Sosyal Bilimler Eğitim Bölümü, Email:erhangormez@hotmaik.com Orcid No: 0000-0003-0752-802X.
} 
the city centre of Van in the 2018-2019 academic year. In the study, the data were collected through an open-ended questionnaire. In the study, in which a quantitative approach was adopted, the data were analyzed using the SPSS 21.0 package program. Frequency and percentage values were used to analyze the data. When the findings obtained as a result of the research are examined, it seen that the students could not adequately explain subjects such as the concept of the map, the criteria to be found on the map, the types of the map, the meanings of the colours used on the map, the meaning of the symbols on the map and the concept of the earth; mostly confuse the concepts of latitude and longitude with the concepts of "parallel and meridian"; mostly confuse the coordinates of Turkey; not have enough sufficiency about locating according to the given coordinates.

Keywords: Map literacy, Social studies, Secondary school, Student

\section{Giriş}

Birey dünyaya geldiği andan itibaren hayatını coğrafi bir mekân içinde sürdürmektedir. Bu mekânla ilgili sahip olunan her faydalı bilgi bireyin hayatını kolaylaştırmakta, onun fiziksel ihtiyaçlarını (barınma, beslenme, giyinme vb.) daha sağlıklı karşılamasına imkân tanımaktadır. Bireyin sahip olduğu ihtiyaçların çok çeşitli olması, bireyi yaşadığı mekânın dışına çıkmasına ve farklı coğrafi çevreleri de tanımasına teşvik etmektedir.

İnsanın dünyaya gelmesiyle başlayan ve çeşitli ihtiyaçlarının giderilmesiyle artan mekân ilişkisi okul yaşantısıyla birlikte çok boyutlu bir hal almaya başlamaktadır. Bu süreçte birey 1-3. sınıf aralığında aldığı hayat bilgisi dersi, 4 ve 7. sınıf arasında da aldığı sosyal bilgiler dersi aracılığıyla yaşadığı mekânı çok boyutlu tanımaya ve önemli coğrafi bilgileri daha sistematik öğrenmeye başlamaktadır. Özellikle birey yaşamı için gerekli mekânsal temel bilgi, beceri ve değerleri, birinci kademeye kıyasla, ikinci kademede yer alan olan sosyal bilgiler dersi ile daha ayrıntılı öğrenebilme imkânına sahiptir.

Bir çalışma alanı olan sosyal bilgiler dersi birçok disiplinin bir araya gelmesinden oluşmuştur. Multi-disipliner bir yapıya sahip olan bu dersin faydalandığı disiplinlerden biri de coğrafyadır. Sosyal Bilgiler Öğretim Program'ında doğrudan coğrafya disiplini ile ilişkili olan İnsanlar, Yerler ve Çevreler adlı öğrenme alanı ile "insanın çevresi ve etkileşimini tanımak, bu konuda çeşitli beceri ve değerleri kullanarak bu etkileşimin neden ve sonuçlarını anlamak ve geleceğe yönelik bireysel ya da toplumsal bakış açısı kazandırabilmek amaçlanmaktadır. Ayrıca bu öğrenme alanı ile bütün sınıf düzeylerinde ögrrencilere araştırma, çevre

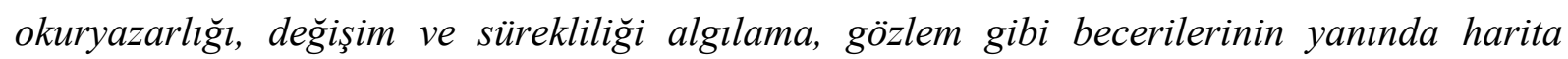


okuryazarlı̆̆ı ve mekânı algılama gibi önemli beceriler de kazandırılmaya çalışılmaktadır” (Mili Eğitim Bakanlığı [MEB], 2018).

Ayrıca güncellenen program doğrultusunda hazırlanan sosyal bilgiler ders kitapları incelendiğinde nitelikli bir harita okuma ve yorumlama becerisi oluşturma adına "konum tarif etme, kroki çizme, ölçek belirleme, harita oluşturma, harita yorumlama, farklı harita türleri hakkında bilgi sahibi olma" gibi önemli konulara yer verildiği görülmektedir. Program, ders içeriğindeki yoğun harita etkinlikleri ile bireyde nitelikli bir harita okuryazarlık becerisini de geliştirmeyi amaçlamaktadır. Üzümcü (2007) aktif öğrenme yöntemleriyle haritalardan en iyi biçimde yararlanmak adına sosyal bilgiler dersinde harita okuryazarlık becerisinin kazandırılması gerektiğine vurgu yapmıştır. $\mathrm{Bu}$ beceri öğrencilerin öncelikle yaşadıkları mekânlarla ilgili olguları anlamalarında önemlidir. Ayrıca harita okuryazarlığı becerisi ile birey haritadaki renklerden, işaretlerden, sembollerden ve harita lejantından yola çıkarak harita üzerinde yorum yapma, analiz etme ve değerlendirme yeterliliğini de kazanacaktır. Harita okuryazarlığı bireylerin mekânı algılamaları, yer-olay bağlantısı kurabilmeleri açısından büyük önem arz etmektedir (Akengin, Tuncel ve Gendek, 2016).

Günlük yaşamda, işte ve toplumda haritaları anlama ve kullanma yeteneği olan harita okuryazarlığı, okuma yazma, artikülasyon ve aritmetik ile birlikte, hayatta kalma ve sosyoekonomik refahın temel ihtiyaçlarını karşılamak için bir kişinin temel yaşam becerilerinin bir parçasını oluşturmaktadır (Clarke, 2003). Okuryazarlık kadar önemli olan bu becerinin erken yaşlarda kazanımı eğitim kurumlarında sistematik bir program anlayışı ile olabilecek bir durumdur. Bu açıdan haritaları iyi okuyabilmek için haritaların genel özelliklerinin öğrenciye çok iyi bir şekilde kavratılması gerekir (Kartal, 2016).

Özellikle sosyal bilgiler dersi aracılığıyla harita okuryazarlığı için yukarıda değinilen bilgiler ilkokul 4. sınıftan itibaren öğrenciye kazandırılmaya çalışılmaktadır. Daha ilerleyen kademelerde birey haritalara baktığında haritayı oluşturan her öğenin, sembolün anlamını ve haritanın hayatımızdaki önemini kavrayacak bilgilerle donatılmış olacaktır. Bu çalışmanın amacı da sosyal bilgiler dersini dört yıl almış ortaokul 8. sınıf öğrencilerinin harita okuryazarlık becerisi konusundaki yeterliliklerini ortaya koymaktır. Alan yazın incelendiğinde ortaokul öğrencilerinin harita okuryazarlığı becerisi ilgili çalışmaların çok sınırlı olduğu (Erol, 2017; Kartal, 2016), çalışmaların genelde öğretmen adaylarına (Balcı, 2015; Duman ve Girgin, 2007; Koç ve Çiftçi, 2016; Kuzey ve Değirmenci, 2017) yönelik olduğu görülmektedir. Bu çalışma sonucunda elde edilen bulguların alandaki bu eksikliği gidereceği ve konuya ilgi duyan 
araştırmacıları harita okuryazarlık becerisinin boyutlarıyla ilgili araştırma yapmaya sevk edeceği umulmaktadır.

\section{Yöntem}

Bu başlık altında araştırmanın modeline, örneklemine, veri toplama araçlarına, verilerin toplanması ve analizi sürecine ilişkin bilgilere yer verilmiştir.

\section{Araştırmanın Modeli}

$\mathrm{Bu}$ çalışma nicel araştırma modellerinden biri olan betimsel bir çalışmadır. Eğitim alanlarında en yaygın kullanılan betimsel model çalışmalarında bir konunun mevcut durumu araştırılarak ortaya konulmaya çalışılır (Gurbetoğlu, 2018). Bu çalışmada da sosyal bilgiler dersini dört yıl almış ortaokul 8. sınıf öğrencilerinin harita okuryazarlık becerisi konusundaki yeterlilikleri değerlendirilmeye çalışılmıştır.

\section{Çalışmanın Evren ve Örneklemi}

Araştırmanın evrenini 2018-2019 eğitim öğretim döneminde Van il merkezinde bulunan ortaokullarda 8. sınıfa giden öğrenciler oluşturmaktadır. Çalışmanın örneklemini de Van İpekyolu ilçesine bağlı Fevzi Çakmak, Tev-İfakat Yavuz ve Cumhuriyet İmam Hatip ortaokulları ile Tuşba İlçesine bağlı Ahmet Yesevi Ortaokulu 8. sınıf öğrencileri oluşturmaktadır. Bu araştırmada olasılık dışı örnekleme türlerinden biri olan amaçlı örnekleme türünden yararlanılmıştır. Bu örneklemde örnek biriminin seçilme şansı, araştırmacının bireysel yargısına bağlıdır (Yıldız, 2017). Örneklem, belirli özelliklere sahip ve araştırma sorularına cevap bulunulacağına inanılan kişilerden seçilir. Bu araştırmada da sosyal bilgiler dersini dört yıl almış olan ortaokul 8. sınıf öğrencileri bu örneklem türü bağlamında değerlendirilmiştir. Örneklem ile ilgili bilgiler tablo 1'de verilmiştir.

Tablo 1. Çalışmanın Örneklemi

\begin{tabular}{cccc}
\hline Okullar & Kodlar & Erkek & Kiz \\
\hline Fevzi Çakmak Ortaokulu & FÇO & 7 & 16 \\
\hline $\begin{array}{c}\text { Tev İfakat Yavuz } \\
\text { Ortaokulu }\end{array}$ & TİYO & 11 & 9 \\
\hline $\begin{array}{c}\text { Ahmet Yesevi Ortaokulu } \\
\begin{array}{c}\text { Cumhuriyet İmam Hatip } \\
\text { Ortaokulu }\end{array}\end{array}$ & AYO & 12 & 10 \\
\hline Toplam & & 8 & 17 \\
\hline
\end{tabular}


Araştırmanın örneklemini 90 ortaokul öğrencisi oluşturmaktadır. Bu öğrencilerin 38’i erkek, 52'si de kız öğrencilerden oluşmaktadır.

\section{Veri Toplama Aracı}

Araştırmada, veriler açık uçlu sorulardan oluşan bir anket formu kullanılarak toplanmıştır. Anketi hazırlanmasında takip edilen süreç aşağıdaki şekilde gösterilmiştir.

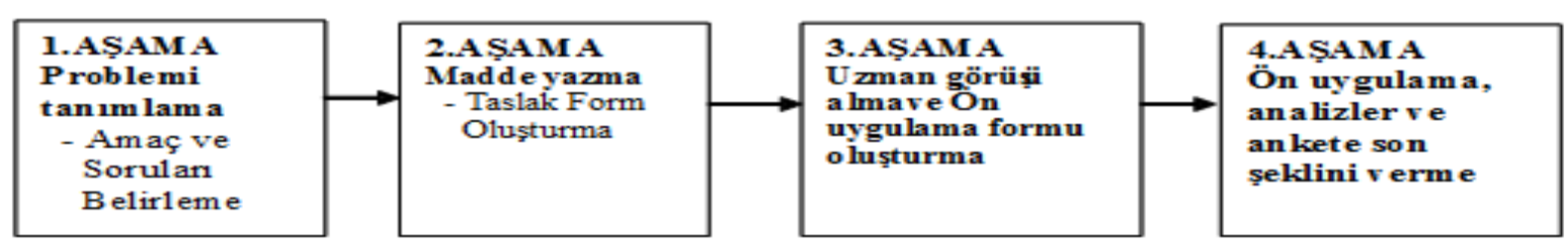

Şekil 1. Anketin hazırlanmasında takip edilen süreç (Büyüköztürk, Akgün, Karadeniz, Demirel ve Kılıç, 2013).

1. Aşama: Bu aşamada çalışmanın konusu dikkate alınarak hem alan yazın incelenmiş hem de alanda uzman kişilerin görüşleri alınmıştır. Çalışmada ortaokul 8. sınıf öğrencilerine sorulacak soruların hazırlanmasında 4, 5, 6 ve 7. sosyal bilgiler ders kitaplarından yararlanılmıştır. Kitap içinde doğrudan coğrafya disiplini ile ilişkili olan İnsanlar, Yerler ve Çevreler öğrenme alanında yer alan ve harita becerileri ile ilişkili konular dikkate alınmıştır. Ayrıca alan yazında harita okuryazarlığı becerisi ile ilgili yapılmış bilimsel çalışmalar incelenmiştir.

2. Aşama: $\mathrm{Bu}$ aşamada çalışmanın amacını ifade eden bir giriş bölümü ile kişisel bilgilerin yer aldığı 11 maddeden oluşan bir taslak form oluşturulmuştur.

3. Aşama: Anketlerde kapsam geçerliliğinin belirlenmesinde uzman görüşlerine başvurmak önemli yöntemlerdendir (Baykul, 2000). Hazırlanan taslak görüşme formu dil ve anlatım denetimi için alanında uzman 2 Türkçe eğitimcisine, soruların konuyla ilişkisi bakımından da 3 sosyal bilgiler öğretmenine inceletilmiştir. Hazırlanan 11 maddelik açık uçlu anket formu 8. sınıfa devam eden 12 öğrenciye uygulanmıştır.

4. Aşama: Öğrencilerden alınan geri dönütler doğrultusunda anlaşılmayan 2 madde formdan çıkarılmış, Türkiye'nin koordinatları ile ilişkili bir soru daha anlaşılır hale getirilmeye çalışılmıştır. Uygulama yapmaya hazır hale getirilen form bazı okullarda bizzat araştırmacı tarafından bazı okullarda da sınıf öğretmenleri tarafından uygulanmıştır. Anket formunu uygulanmadan önce araştırmacı çalışmanın niçin yapıldı̆̆ 1 hakkında öğrencileri bilgilendirmiş ve öğrencilerden samimi biçimde görüşlerini anket formuna yazmalarını istemiştir. 


\section{Verilerin Analizi}

Nicel bir yaklaşımın benimsendiği çalışmada veriler SPSS 21.0 paket programı kullanılarak çözümlenmiştir. Nicel verilerin analizi için frekans ve yüzdelik değerlere bakılmıştır. Analiz sonucu elde edilen veriler bulgular başlığı altında tablolaştırılarak verilmeye çalışılmıştır.

\section{Etik Kurul Kararı}

Van Yüzüncü Yıl Üniversitesi Sosyal ve Beşeri Bilimleri Yayın Etik Kurulu'nun, 07/07/2020 tarih ve 2020/07-04 sayılı kararı gereği çalışma açısından Sosyal ve Beşeri Etik Kuralları ve İlkeleri çerçevesinde herhangi bir sakınca olmadığına karar verilmiştir.

\section{Çalışmanın Geçerliliği ve Güvenirliği}

$\mathrm{Bu}$ çalışmanın kapsam geçerliğini artırmak için alanında uzman üç sosyal bilgiler öğretmeni ve dil uzmanından görüş alınmıştır. Uzman görüşüyle "ankette yer alan maddeler ihtiyaç duyulan olgusal ve/veya yargısal verileri kapsamada ve toplamada ne derece yeterlidir?” sorusunun cevabı aranmıştır (Öztürk, 2005). Yine anketin geçerliliğini artırmak için araştırmacı veri toplama sürecine doğrudan katılarak çalışmanın amacı ve kendi statüsü hakkında bilgi vermiş, katılımcılara soru formunu cevaplarken onları açık sözlü olmaları konusunda teşvik etmiştir. Çalışmanın güvenirliği artırmak için araştırmada veri kaynağı olan çalışma grubu açık biçimde tanımlanmış, katılımcılardan elde edilen verilerin nasıl toplandığı ve nasıl analiz edildiği ayrıntılı biçimde açıklanmıştır.

\section{Bulgular}

$\mathrm{Bu}$ başlık altında açık uçlu anket formundan elde edilen veriler tablolaştırılmaya çalışılmıştır.

1. Harita kavramın ne olduğu hakkında ulaşılan bulgular.

Tablo 2. Harita Kavramının Ne Olduğuna Dair Öğrenci Açıklamaları

\begin{tabular}{lll}
\hline Açıklamalar & f & $\mathbf{\%}$ \\
\hline Yol bulmada yardımcı olur & 32 & 35,5 \\
\hline Ülkeleri ve şehirleri gösterir & 20 & 22,2 \\
\hline Bir yerin kuşbakışı ölçümünün kağıda aktarımı & 19 & 21,1 \\
\hline Yön bulmak için kullanılır & 11 & 12,2 \\
\hline Bir yerin konumunu gösterir & 8 & 8,8 \\
\hline Dünyayı tanımamızı sağlar & 7 & 7,7 \\
\hline Bir yerin coğrafi özelliklerini gösterir & 5 & 5,5 \\
\hline
\end{tabular}


Tablo 2'de öğrencilerin harita kavramının bilimsel açıklamasından ziyade haritanın işlevine yönelik bilgi verdikleri görülmektedir. Haritanın ne olduğuyla ilgili öğrencilerin \%21,1'in "bir yerin kuşbakışı ölçümünün kâğıda aktarımı” şeklinde bir ifade kullandıkları; haritanın işleviyle ilgili olarak da öğrencilerin \% 35,5'inin "yol bulmada yardımcı olur, \% 22,2'sinin “ülkeleri ve şehirleri gösterir, \% 12,2'sinin “yön bulmak için kullanır”, \% 8,8'inin “bir yerin konumunu gösterir”, \%7,7’sinin “dünyayı tanımamızı sağlar”, \%5,5’inin "bir yerin coğrafi özelliklerini gösterir” şeklinde açıklamalar yaptığı görülmektedir.

2. Harita çiziminde bulunması gereken kriterlere ilişkili bulgular

Tablo 3. Harita Çiziminde Bulunması Gereken Kriterler İlgili Öğrenci Açıklamaları

\begin{tabular}{lcl}
\hline Açılamalar & $\mathbf{f}$ & $\mathbf{\%}$ \\
\hline Ölçeğin olması & 38 & 42,2 \\
\hline Bilmiyorum & 26 & 28,8 \\
\hline Bir yerin kuşbakışının olması & 22 & 24,4 \\
\hline Belirli bölgelerin olması & 10 & 11,1 \\
\hline Koordinatların olması & 9 & 10 \\
\hline Kalem, kağıt ve cetvelin olması & 6 & 6,6 \\
\hline Dağ, yol, sınırlar olmalı & 4 & 4,4 \\
\hline
\end{tabular}

Tablo 3 incelendiğinde öğrencilerin \% 28,8'inin harita çiziminde bulunması gereken kriterleri bilmedikleri; \% 42,2'sinin bu kriterlerde "ölçeğin olması”, \% 24,4'ünün "bir yerin kuşbakışının olması”, \% 11,1'inin "Belirli bölgelerin olması”, \% 10'nun "Koordinatların olması", \% 6,6'sının “Kalem, kağıt ve cetvelin olması” ve \% 4,4'ünün de “dağ, yol, sınırlar olmalı" şeklinde açıklama yaptıkları görülmektedir.

3. Harita türlerine ilişkin ulaşılan bulgular

Tablo 4. Harita Türlerine İlişkin Öğrenci Açıklamaları

\begin{tabular}{lll}
\hline Açıklamalar & $\mathbf{f}$ & $\mathbf{\%}$ \\
\hline Türkiye Siyasi harita & 40 & 44,4 \\
\hline Türkiye fiziki haritası & 37 & 41,1 \\
\hline Türkiye coğrafi haritası & 31 & 34,4 \\
\hline Türkiye haritası & 28 & 31,1 \\
\hline Dünya haritası & 19 & 21,1 \\
\hline Bilmiyorum & 14 & 15,5 \\
\hline Türkiye beşeri haritası & 5 & 5,5 \\
\hline Tarihi harita & 4 & 4,4 \\
\hline Bölge haritası & 3 & 3,3 \\
\hline
\end{tabular}

Tablo 4 incelendiğinde öğrencilerin \% 15,5'nin harita türlerini bilmedikleri; sırasıyla \% 44,4’ünün “Türkiye siyasi haritas1”, \% 41,1'inin “Türkiye fiziki haritası”, \%34,4’ünün “Türkiye coğrafi haritası”, \% 31,1'inin “Türkiye haritası”, \%21,1'inin "dünya haritası”, \% 5,5’inin “Türkiye beşeri haritası”, \% 4,4'ünün “tarihi harita”, \% 3,3’ünün de "bölge haritası" 
şeklinde harita türleri ifade ettikleri görülmektedir. Verilen cevaplardan öğrencilerin tamamının kullanım amaçlarına göre harita türleri hakkında görüş paylaştıkları görülmektedir.

4. Haritada kullanılan renklere ilişkin ulaşılan bulgular

Tablo 5. Haritada Kullanılan Renkler İle İlgili Öğrenci Açıklamaları

\begin{tabular}{lll}
\hline Açıklamalar & f & $\mathbf{\%}$ \\
\hline Kahverengi-dağlık, yüksek yer & 37 & 41,1 \\
\hline Mavi-deniz, su & 26 & 28,8 \\
\hline Bilmiyorum & 22 & 24,4 \\
\hline Yeşil-alçak yükseklik & 18 & 20 \\
\hline Yeşil-ormanlık & 16 & 17,7 \\
\hline Renkler yüksekliğe olarak farklılaşır & 16 & 17,7 \\
\hline Bir yerin diğer yere olan farklılığını gösterir & 6 & 6,6 \\
\hline Sarı-tarım alanı & 4 & 4,4 \\
\hline Sarı-orta yükseklik & 3 & 3,3 \\
\hline
\end{tabular}

Tablo 5 incelendiğinde öğrencilerin \% 24,4'ünün haritalarda kullanılan renkleri bilmedikleri; \% 41,1'inin dağlık ve yüksek kesimleri kahverengi ile \% 28,8'inin deniz ve su bölgelerini mavi renkle, \% 20'si alçak yerleri ve \% 17,7'si ormanlık alanları yeşil rengi ile, \% 4,4’ü tarım alanlarını ve \% 3,3’ü orta yüksekliği sarı rengi ile ilişkilendirdikleri görülmektedir. Ayrıca öğrencilerin \% 17,7'si renklerin yüksekliğe göre farklılaştığını ve yine \% 6,6'lık bir oranda renklerin bir yerin diğer yere olan farklılığını göstermek için kullanıldığını ifade etmiştir. Bu sonuçlar öğrencilerin haritalarda kullanılan renkleri kullandıkları sembollerle özdeşleştirdikleri ve renklerin haritada doğru kullanımı konusunda yeterli bilgiye sahip olmadıklarını ortaya koymaktadır.

\section{Haritada kullanılan işaretlere ilişkin bulgular}

Tablo 6. Haritada Kullanılan İşaretler Hakkında Öğrenci Açıklamaları

\begin{tabular}{lll}
\hline Açılamalar & f & $\mathbf{\%}$ \\
\hline Bilmiyorum & 46 & 51,1 \\
\hline Diğer (havayolu, demiryolu, koordinat, başkent, il, göl, liman, baraj, ülke sınırı) & 44 & 48,8 \\
\hline Bilgi veren işaretler (lejant) & 20 & 22,2 \\
\hline
\end{tabular}

Tablo 6 incelendiğinde öğrencilerin \% 51,1'inin haritada kullanılan işaretlerin ne anlama geldiğini bilmediği, \% 48,8’inin belirli işaretleri (havayolu, demiryolu, koordinat, başkent, il, göl, liman, baraj, ülke sınırı) bildikleri, \% 22,2'sinin bu işaretleri lejant olarak adlandırdıkları görülmektedir. $\mathrm{Bu}$ sonuçlar öğrencilerin haritalarda kullanılan semboller hakkında yeterli olmayan, eksik bilgiye sahip olduklarını göstermektedir. 
6. Yeryüzü kavramının ne olduğuna ilişkin ulaşılan bulgular

Tablo 7. Yeryüzü Kavramının Ne Olduğuna İlişkin Öğrenci Açıklamaları

\begin{tabular}{lll}
\hline Açıklamalar & f & \% \\
\hline Bilmiyorum & 37 & 41,1 \\
\hline Dağlar, ovalar, denizler & 19 & 21,1 \\
\hline Derin, sı̆̆, tümsek ve yuvarlak & 9 & 10 \\
\hline Yaşadığımız yerin fiziksel özellikleri & 8 & 8,8 \\
\hline Yer kabuğu & 7 & 7,7 \\
\hline Dünyadaki kara ve denizler & 5 & 5,5 \\
\hline
\end{tabular}

Tablo 7 incelendiğinde öğrencilerin \% 41,1'inin yeryüzü kavramını bilmedikleri, \% 21,1'inin yeryüzünü “dağlar, ovalar, denizler” olarak, \% 10’nun “derin, sı̆̆, tümsek ve yuvarlak" olarak, \% 8,8'inin “yaşadığımız yerin fiziksel özellikleri” olarak, \% 7,7'sinin “yer kabuğu” olarak, \% 5,5'inin de “dünyadaki kara ve denizler” olarak ifade ettikleri görülmektedir.

7. Coğrafi konumu belirlemeye yarayan hayali çizgilere ilişkin ulaşılan bulgular

Tablo 8. Harita Üzerinde Bir Yerin Coğrafi Konumunu Belirlemeye Yarayan Hayali Çizgiler Hakkında Öğrenci Açıklamaları

\begin{tabular}{lll}
\hline Açıklamalar & f & $\mathbf{\%}$ \\
\hline Meridyen & 40 & 44,4 \\
\hline Boylam & 37 & 41,1 \\
\hline Enlem & 33 & 36,6 \\
\hline Paralel & 28 & 31,1 \\
\hline Bilmiyorum & 18 & 20 \\
\hline Ekvator & 11 & 12,2 \\
\hline Koordinatlar & 6 & 6,6 \\
\hline Eksen & 4 & 4,4 \\
\hline
\end{tabular}

Tablo 8 incelendiğinde öğrencilerin \% 20'sinin konum belirlemeye yarayan hayali çizgileri bilmedikleri, \% 44,4'ünün bu hayali çizgileri “meridyen”, \% 41,1'inin “boylam”, \% 36,6'sının “enlem”, \% 31,1'inin “paralel”, \% 12,2'sinin “ekvator”, \% 6,6'sinın “koordinat” ve \% 4,4'nün “eksen” olarak ifade ettikleri görülmektedir. Tablodan öğrencilerin coğrafi koordinatları belirlemek amacıyla kullanılan enlem ve boylam kavramlarının çoğunlukla "paralel ve meridyen” kavramlarıyla karıştırıldığı anlaşılmaktadır.

8. Türkiye'nin koordinatlarına ilişkin ulaşılan bulgular

Tablo 9. Türkiye'nin Koordinatları İle İlgili Öğrenci Görüşleri

\begin{tabular}{lll}
\hline Açıklamalar & f & $\mathbf{\%}$ \\
\hline Bilmiyorum & 32 & 35,5 \\
\hline $\mathbf{2 6 - 4 5}$ kuzey enlemler; $\mathbf{3 6 - 4 2}$ doğu paralelleri & 30 & 33,3 \\
\hline $\begin{array}{l}\text { Karıştıran veya yanlış bilgi veren (26-45 doğu meridiyenleri;36-45 kuzey paralelleri } \\
\text { gibi) }\end{array}$ & 17 & 18,8 \\
\hline
\end{tabular}


Tablo 9 incelendiğinde öğrencilerin \% 35,5'inin Türkiye'nin koordinatlarını bilmedikleri, \% 33,3’ünün bu koordinatları karıştırdıkları ve \% 18,8’inin de “26-45 kuzey enlemler; 36-42 doğu paralelleri” olarak ifade ettikleri görülmektedir. Bu sonuçlar öğrencilerin Türkiye'nin koordinatları konusunda yeterli olmayan ve karıştırılan bir bilgiye sahip olduklarını ortaya koymaktadır.

9. Koordinat bilgisiyle haritada yer tespitine ilişkin bulgular

Tablo 10. Koordinat Bilgisiyle Haritada Yer Tespiti Yapmaya İlişkin Öğrenci Açıklamaları

\begin{tabular}{lll}
\hline Açılamalar & f & \% \\
\hline Erzurum & 40 & 44,4 \\
\hline Bilmiyorum & 29 & 32,2 \\
\hline Karadeniz -Trabzon & 19 & 21,1 \\
\hline
\end{tabular}

Tablo 10 incelendiğinde öğrencilere verilen haritada $40^{\circ}$ kuzey paraleli ile $42^{\circ}$ doğu meridyeninin kesiştiği yeri tespit etmeleri istenmiştir. Öğrencilerin \% 32,2'sinin verilen koordinatla yer tespiti yapmayı bilmedikleri, \% 44,4'ünün doğru tespit yaptıkları (Erzurum), \% 21,1'inin yanlış tespit yaptıkları görülmektedir. Bu sonuçlar öğrencilerin çoğunluğunun verilen koordinatları haritada gösterme konusunda yetersiz olduğunu ortaya koymaktadır.

\section{Tartışma ve Sonuç}

Harita okuryazarlığı becerisi bireyin yaşadığı mekânı anlamlandırması bakımından kazanması gereken önemli becerilerden biridir. Bu becerinin erken yaş dönemlerinde eğitim kurumlarında sistematik bir anlayışla kazandırılmasında sosyal bilgiler dersi özel bir yere sahiptir. Bu çalışma ile de sosyal bilgiler dersini 4 yıl boyunca almış 8 . sınıf öğrencilerinin harita okuryazarlık becerisi ile ilgili yeterlilikleri tespit edilmeye çalışılmıştır.

Çalışmada elde edilen bulgular incelendiğinde; harita kavramının ne olduğu ile ilgili öğrencilerin detaylı bir bilgiye sahip olmadıkları, bu kavramı daha çok işlevsellik boyutunu (yol bulmada yardımcı olur, ülkeleri ve şehirleri gösterir, yön bulmak için kullanılır gibi) dikkate alarak açıkladıkları görülmektedir. Disiplinler arası yaklaşımla oluşturulmuş sosyal bilgiler dersi bünyesinde yer alan önemli disiplinlerden biri de coğrafyadır. Doğrudan “İnsanlar, Yerler ve Çevreler” adlı öğrenme alanında da coğrafya disiplinin temelini oluşturan haritalar konusuna kapsamlı yer verilmiştir. Çok fazla olgu ve kavramlardan oluşan coğrafya disiplinine ilişkin konuların etkili öğretimi için alan gezileri, uygulamalı harita oluşturma etkinlikleri önemlidir. Erol'un (2017) “Ortaokul Öğrencilerinin Harita Okuryazarlık Becerilerine İlişkin Bir Değerlendirme" konulu çalışmasında ortaokul 7. sınıf öğrencilerinin harita okuryazarlık 
düzeylerinin çoğunlukla orta düzeyde olduğu ve bunun nedenin de sınıfta öğrenilenlerin sadece ezberlendiği, öğrenilen konuların yeterince pratiğe dökülmediği tespit edilmiştir.

Bir diğer bulguda öğrencilerin harita çizimlerinde bulunması gereken kriterlerin ne olduğuyla ilgili yeterlilikleri incelenmiştir. Öğrencilerin 1/3'nün bu kriterlerin ne olduğunu bilmedikleri, geriye kalan öğrencilerin de harita çiziminde kullanılan kriterleri (ölçek, kuşbakışı, koordinat gibi) eksik ifade ettikleri tespit edilmiştir. Bu bulgunun doğrudan ilk bulguyla da bağlantısı söz konusudur. Genel olarak yeryüzünün tamamının veya bir parçasının kuşbakışı görünümünün matematik yöntemlerle istenilen ölçeğe göre küçültülerek, özel işaretleriyle bir düzleme çizilmiş örneği (Ünlü, Üçışık ve Özey, 2002) olarak tanımlanan haritanın bilimsel açıklamasının öğrenciler tarafından biliniyor olması, bir harita çizimi için gerekli olan kriterlerin ne olduğunun da bilinmesi anlamına gelmektedir. Birçok derste olduğu gibi sosyal bilgiler dersinde de gereksiz ayrıntılardan ziyade hayatta karşılığı olan pratik bilgilerin aktarımı önemlidir. Buğdaycı ve Bildirici (2009) öğretimin genel amacının öğrencilere yeteri kadar anahtar bilgiler kazandırmak, fakat gerekli olduğu zaman ve yerlerde, bilgilerin sağlanma ve kullanma yollarını öğretmek olduğunu ifade etmişlerdir. Bu bakımdan birçok disiplini içeren sosyal bilgiler derslerindeki kavramların öğretiminde, öğrencilere bol örnek verilmesi, kavramların mümkün olduğunca görsel materyallerle desteklenmesi, uygun öğretim tekniklerinin kullanılması, kavramın öğretimini kolaylaştırır (Yazıcı ve Samancı, 2003).

Diğer bulguda harita türleri hakkında öğrencilerin görüşleri incelenmiştir. Öğrencilerin genelde kullanım amaçlarına göre haritaları "Türkiye siyasi haritası, Türkiye fiziki haritası, Türkiye coğrafi haritası, Türkiye haritası, dünya haritası” şeklinde sıraladıkları ama ölçeklerine göre harita türleri hakkında da bir bilgiye sahip olmadıkları sonuçlarına ulaşılmıştır. Yukarıda da değinildiği gibi coğrafya öğretiminin temelini haritalar oluşturmaktadır. Derslerde en çok kullanılan bu materyallerin tam olarak ne anlama geldiği, türleri gibi konular uygulama etkinlikleri ile öğrencilere kazandırılmaya çalışılmalıdır. Diğer bilim dallarında olduğu gibi coğrafya disiplini içindeki soyut kavram ve konuların öğretiminde ezber bir yöntem izlemek konuların öğrenilmemesindeki önemli nedenlerden biridir. Pekdemir ve Polat (2016) haritaların sosyal bilgiler dersinde işlevi önemli bir materyal olduğunu; derste tarihi, coğrafi, siyasi haritalardan faydalanıldığını ve ayrıca çocuklara yaşadıkları yerin, bölgenin ve ülkenin dünya üzerindeki konumu hakkında bilgi verdiğini ifade etmişlerdir. Bir diğer çalışmada da Sönmez ve Aksoy (2012) özel ve devlet okullarında öğrenim gören ikinci kademe öğrencilerinin harita beceri düzeylerini ortaya koymaya çalışmıştır. Çalışma sonucunda özel okullarda öğrenim 
gören öğrencilerin harita becerilerinin, devlet okullarında öğrenim gören öğrencilerden; büyük şehirde öğretim gören öğrencilerin yine harita beceri düzeylerinin, şehirde öğretim gören öğrencilere göre daha iyi olduğu sonuçlarına ulaşmıştır.

Diğer bulguda haritalarda kullanılan renkler konusunda öğrencilerin ne bildikleri tespit edilmeye çalışılmıştır. Öğrencilerin yaklaşık 1/4'nün haritada kullanılan renklerin ne anlama geldiğini bilmedikleri, geriye kalanların büyük çoğunluğunun da kahverengini yükseklikle veya dağlık alanla, mavi rengini su veya denizle, yeşil rengini ormanlık alanla ilişkilendirdikleri sonucuna ulaşılmıştır. $\mathrm{Bu}$ sonuçlar öğrencilerin haritada kullanılan renkleri, o renkleri çağnıştıran nesnelerle ilişkilendirerek yorumladıkları, renklerin anlamlarının ezberlendiğinden dolayı karıştırıldığını ortaya koymaktadır. Çelikkaya (2002) fiziki haritada kullanılan renklerin haritanın daha iyi anlaşılmasını sağladığını ifade etmiş, en yüksek kesimlerin koyu kahverengi ile denizlerin derin yerlerinin de koyu mavi rengi ile gösterdiğini ifade etmiştir. Öğrencilere haritada kullanılan renklerin ne anlama geldiklerini öğretmenin en etkili yöntemi sınıf ortamında harita oluşturma ve harita yorumlama gibi etkinliklere sık sı yer verilmesidir. Birçok soyut olgu ve kavramdan oluşan coğrafya dersinin konuları ezberden ziyade öğrencinin merkezde olduğu etkinlikler ile daha etkili öğretilebilir.

Diğer bir bulguda haritada kullanılan işaretler konusunda öğrencilerin ne bildikleri tespit edilmeye çalışılmıştır. Araştırmaya katılan öğrencilerin çoğunluğunun lejant olarak ifade edilen haritadaki sembollerin ne anlama geldiğini bilmedikleri tespit edilmiştir. 8. sınıf öğrencilerinin haritada kullanılan sembollerin ne anlama geldiğini bilmemeleri, harita yorumlama konusunda da yetersiz olduklarını ortaya koymaktadır. Akar (2008) “ïlköğretim 6. sınıf öğrencilerinin harita kullanma düzeylerinin ve harita kullanımına ilişkin öğretmen görüşlerinin değerlendirilmesi” konulu çalışmasında araştırmaya katılan 821 öğrencinin \% 45’inin lejantları okuma becerilerinin orta düzeyde olduğunu ortaya koymuştur. Aynı çalışmada araştırmaya katılan öğretmenlerin sadece 14'ü (\% 23,3) öğrencilerin dilsiz bir haritayı lejantlara bakarak yorumlama becerilerinin “Orta” düzeyin üstünde yeterli olduğunu ifade etmişlerdir. Bu sonuç da çalışmada ulaşılan bulguyu destekler niteliktedir. Çünkü harita becerisi demek öncelikle sembolleri anlama ve yorumlama becerisi demektir (Mcclure, 1992).

Diğer bir bulguda öğrencilerin yeryüzü kavramının ne olduğuyla ilgili bilgileri tespit edilmeye çalışılmıştır. Araştırma sonucunda öğrencilerin çoğunluğunun yeryüzü kavramını bilmedikleri, geriye kalanların da bu kavramı sırasıyla "dağlar, ovalar, denizler, derin, sı̆̆, tümsek ve yuvarlak, yaşadığımız yerin fiziksel özellikleri, yer kabuğu, dünyadaki kara ve denizler ve havadaki olaylara bağlı oluşan şekiller" şeklinde tanımladıkları sonucuna 
ulaşılmıştır. Bu sonuç da coğrafi kavramların öğretiminde alan ve arazi uygulamalarının önemini ortaya koymaktadır. Harita kullanma ve harita okuma becerilerinin kazandırılabilmesi için öğretilmesi gereken kavramların dan biri de yeryüzü şekli kavramıdır (Nas, 2000). Yeryüzü kavramının öğretiminde haritaların etkili kullanımı, bu kavramların haritalar aracılığıyla kavratılmaya çalışılması ezbere öğrenmenin olumsuz etkilerini asgari düzeye indirgeyecektir. Yapılan birçok çalışma (Çalışkan, 2015; Özgen, 2010; Yılmaz, 1997) fiziki coğrafya konularının sınıf ortamında işlenmesinin pek verimli olmadığını, öğrencileri ezberciliğe sevk ettiğini ortaya koymaktadır. Öğrencilerin yaşadıkları yerlerdeki yeryüzü şekillerini görerek, genel bir çıkarımda bulunmaya çalışmaları coğrafya öğretiminde önemli bir metottur. $\mathrm{Bu}$ mantıkla yapılan alan gezilerinde öğrenciler önemli coğrafi yapıları yerinde gördükleri gibi kendi yaşadıkları yerin de yeryüzü özellikleri hakkında önemli bilgiler elde etmektedir. 2018 yılında güncellenen Sosyal Bilgiler Öğretim Programı okul dışı ortamların sosyal bilgilere ait önemli kavramları öğretmede önemli olduğuna değinmektedir (MEB, 2018). Akınoğlu (2005) “coğrafya eğitiminin etkililiği ve sorunları” adlı çalışmasında coğrafya eğitiminin işlevselliğinin önemine ve hayatta yaramayan bilginin gereksizliğine değinmiştir. Coğrafya eğitimi aşamalı biçimde önce bireye yaşadığı çevreyi, içinde bulduğu yerin özelliklerini ve sonrasında da dünyayı öğretmelidir.

Bir diğer bulguda haritada bir yerin coğrafi konumunu belirlemeye yarayan hayali çizgilerin ne olduğu konusunda öğrenci yeterliliği tespit edilmeye çalışılmıştır. Öğrencilerin enlem ve boylam kavramlarını "paralel ve meridyen” kavramlarıyla karıştırdıkları tespit edilmiştir. Kayacan’ın (2010) “İlköğretim altıncı sınıf öğrencilerinin coğrafi koordinatlarla ilgili kavram yanılgıları" konulu çalışmasında öğrencilerin coğrafi koordinatlar konusu ile ilgili kutup noktası, kutup dairesi, dönence, ekvator, başlangıç meridyeni, paralel, meridyen, enlem, boylam kavramlarını anlama seviyelerini ve bu kavramlarla ilgili yanılgılarını ortaya koymaya çalışmıştır. Araştırma sonucunda öğrencilerin araştırılan kavramları yeterli düzeyde anlayamadıkları ve bu kavramlarla ilgili birçok kavram yanılgısına sahip oldukları tespit edilmiştir. Benzer bir çalışma da Boz ve Çoban (2019) tarafından yapılmıştır. 585 öğrencinin katıldığı araştırmada öğrencilerin yaklaşık \% 7'sinin harita kavramını, \% 6'sının ölçek, \% 6'sının yerel saat, \% 9'unun özel konum, \% 19'unun matematik konum, \% 15'inin paralelenlem ve \% 13'ünün ise meridyen-boylam kavramlarını anladıkları ortaya çıkmıştır. Araştırma sonunda, öğrencilerin araştırılan kavramları yeterli düzeyde anlayamadıkları, bu kavramlarla ilgili birçok kavram yanılgısına sahip oldukları ve bu kavramları birbirleriyle karıştırdıkları tespit edilmiştir. 
Diğer bir bulguda Türkiye'nin koordinatları konusunda öğrenci yeterlilikleri tespit edilmeye çalışmıştır. Çalışma sonucunda öğrencilerin çoğunluğunun Türkiye'nin koordinatlarını bilmedikleri veya karıştırdıkları sonuçlarına ulaşılmıştır. Coğrafya disiplinine ait soyut konu ve kavramların öğretilmesinde genellikle ciddi sıkıntılar yaşanmaktadır. Bilişsel, duyuşsal ve devinişsel olmak üzere üç boyutta yapılması gereken coğrafya öğretiminin sadece bilişsel boyutuna odaklanılması soyut konuların öğretiminin ezber düzeyde kalmasına veya karıştırılmasına neden olmaktadır. Memişoğlu ve Öner (2013) “sosyal bilgiler dersinde öğrenci ve öğretmen görüşlerine göre coğrafya konularının öğretimi” konulu çalışmasında öğretmenler, öğrencilerin koordinatlar, dünyanın şekli ve hareketleri ile ilgili konuları anlamakta zorluk çektiklerini ifade etmişlerdir. Akar (2008) "ilköğretim 6. sınıf öğrencilerinin harita kullanma düzeylerinin ve harita kullanımına ilişkin öğretmen görüşlerinin değerlendirilmesi” konulu çalışmasında araştırmaya katılan 60 öğretmenin 23'nün orta düzeyde öğrencinin paralel ve meridyenleri olan bir haritada Hatay’ın coğrafi konumunu söyleyebileceğini ifade etmiştir. Öğretmenlerin çoğunluğunun koordinatlar konusunda öğrencileri yeterli görmemeleri uygulamaya dönük bir coğrafya eğitiminin eksikliğinin bir sonucudur.

En son bulgu incelendiğinde koordinatları verilmiş bir yeri haritada tespit etme konusunda öğrencilerin yetersiz olduğu görülmektedir. Verilen bir koordinatta yer veya konum belirleme önemli harita okuma becerilerinden biridir. Bu becerilerin öğrenciler tarafindan içselleştirilmesi ve tam manasıyla anlaşılabilmesi uygulamalı ve öğrencinin merkezde olduğu bir coğrafya eğitimi ile mümkündür. Akkuş ve Kuzey’in (2018) ortaokul 8. sınıf öğrencilerinin harita ve yön becerilerine sahip olma ve bu becerileri yaşama aktarabilme durumlarını tespit etmeye yönelik yaptıkları çalışmada öğrencilere koordinatları verilmiş olan dilsiz bir haritada İskenderun limanının konum ve koordinatlarını yazmaları istenmiştir. Araştırma sonucunda öğrencilerin haritada konum ve koordinat belirleme becerisini yaşama aktarmada başarılı oldukları, ancak bazı öğrencilerin enlem paralel, boylam meridyen kavramlarını karıştırdıkları sonucuna ulaşmışlardır.

Çalışmada ulaşılan bulgular genel olarak değerlendirildiğinde öğrencilerin harita okuryazarlık becerisini oluşturan yeterlilikler konusunda karıştırılan ve tam manasıyla anlaşılmayan bilgilere sahip oldukları görülmektedir. Kişinin hem kendi çevresindeki hem de geniş bir alandaki olguları anlamada ihtiyaç duyduğu becerilerden biri olan harita okuryazarlık becerileri haritalarda bulunan bilgileri tanımlama, yorumlama, analiz etme ve değiştirme yeteneğini, görsel algı ve becerileri içerir ve beynin her iki yarıküresinin de kullanılmasını gerektirir. Bonnet (2003) bireyin yaşam boyunca ihtiyacı olacak harita okuryazarlığı becerisinin 
arzu edilir düzeyde olması için ortaokul kademesinin önemine dikkat çekmiştir. Bu açıdan ortaokul döneminde bireyin alacağı nitelikli bir coğrafya eğitimi bu becerinin ediminde oldukça önemlidir. Bu çalışmada ilkokul ve ortaokul kademelerinde alınan sosyal bilgiler dersinin öğrencilerin harita okuryazarlık becerisine olan katkısı hazırlanmış olan anket formuyla tespit etmeye çalışmıştır.

\section{Öneriler}

Harita okuryazarlığ etkinliklerinin teorik bilgiler aktarıldıktan sonra uygulamalı etkinliklerle pekiştirilmesi gerekmektedir. Özellikle ders kitapları ile birlikte öğrencilere dağıtılan çalışma kitaplarında harita oluşturma etkinliklerine, dilsiz harita uygulamalarına yer verilebilir. Ayrıca gelişen teknoloji ile birlikte farklı yazılımlar kullanılarak sınıfta öğrenciler ile harita oluşturma etkinlikleri yapılabilir. Coğrafya gibi birçok kavram ve olgudan oluşan bir disiplinde konuların somutlaştırılarak öğretimine gereken önem verilmeli. Hem klasik hem de dijital haritalar kullanılarak önemli bir beceri olan harita okuryazarlı̆̆ı öğrencilere kazandırılmaya çalışılmalıdır. Ayrıca coğrafi konuların somutlaştırılmasında 2018 güncel programda önemi vurgulanan alan ve saha gezileri sadece programda bir öneri olarak kalmamalı, okulların sistematik ve planlı olarak yeri geldiğinde saha ve alan çalışmalarına çıkmaları teşvik edilmelidir.

\section{Makalenin Bilimdeki Konumu}

Sosyal Bilgiler Eğitimi/Coğrafya Eğitimi

\section{Makalenin Bilimdeki Özgünlüğü}

Diğer bilim dallarında olduğu gibi coğrafya disiplini içindeki soyut kavram ve konuların öğretiminde ezber bir yöntem izlemek konuların öğrenilmemesindeki önemli nedenlerden biridir. Harita oluşturma veya harita yorumlama becerilerinin uygulamalı etkinlikler ile öğretimi konusu alan yazında üzerine çalışılan konulardadır. Yapılan çalışmaların genelde öğretmen ve öğretmen adaylarına yönelik olması, harita okuryazarlık becerisinin ilkokul veya ortaokul düzeyinde yeterli düzeyde incelenmemesi alan yazın bakımından bir eksiklik olarak görülmektedir. $\mathrm{Bu}$ nedenle çalışma ortaokul öğrencilerinin harita okuryazarlık becerisi yeterliliklerini tespit etmek ve konuya ilgi duyan araştırmacıları farklı sınıf kademelerini incelemeye teşvik etmek bakımından özgün bir çalışmadır. 


\section{Kaynaklar}

Akar, B. (2008). Illköğretim 6. sınıf öğrencilerinin harita kullanma düzeylerinin ve harita kullanımına ilişkin ögretmen görüşlerinin değerlendirilmesi. Yüksek lisans tezi, Sosyal Bilimler Enstitüsü Mustafa Kemal Üniversitesi, Hatay.

Akengin, H., Tuncel, G. ve Cendek, M., E. (2016). Öğrencilerde harita okuryazarlığının geliştirilmesine ilişkin sosyal bilgiler öğretmenlerinin görüşleri. Marmara Coğrafya Dergisi, 34, 61-69.

Akınoğlu, O. (2005). Coğrafya eğitiminin etkililiği ve sorunları. Marmara Coğrafya Dergisi, 12, 77-96.

Akkuş, Z. ve Kuzey, M. (2018). Ortaokul öğrencilerinin harita ve yön becerilerine sahip olma ve bu becerileri yaşama aktarabilme durumları üzerine bir değerlendirme. Millî Ĕgitim Dergisi, 47(218), 201-233.

Balcı, A. (2015). Coğrafya öğretmen adaylarının coğrafi arazi uygulamalarındaki harita okuryazarlıklarını tespite yönelik bir araştırma. Akademik Sosyal Araştırmalar Dergisi, 3(10), 16-34.

Baykul, Y. (2000). Eğitimde ve psikolojide ölçme: klasik test teorisi ve uygulaması. Ankara: ÖSYM Yayınları.

Bonnet, A. (2003). Geography as a world discipline: Connecting popular and academic imaginations. Area, 35(2), 123-138.

Boz, E. ve Çoban, A. (2019). Ortaokul öğrencilerinin harita ve coğrafi koordinatlarla ilgili kavramları anlama düzeyleri ve kavram yanılgılar. II. Uluslararası Coğrafya Eğitimi Kongresi (UCEK-2019). Eskişehir, Türkiye.

Buğdaycı, İ. ve Bildirici, İ. Ö. (2009). Harita kullanımının coğrafya eğitimindeki önemi. 12. Türkiye Harita Bilimsel ve Teknik Kurultayı, Ankara.

Büyüköztürk, Ş., Kılıç Çakmak, E., Akgün, Ö.E., Karadeniz, Ş. ve Demirel, F. (2014). Bilimsel araştırma yöntemleri. Ankara: PegemA Yayıncılık.

Clarke, D. (2003). Are you functionally map literate? In: Cartographic renaissance. 21st International Cartographic Conference (ICC10-16 August 2003), Durban, South Africa.

Çelikkaya, T. (2002). İlköğretim 1. kademe sosyal bilgiler dersi coğrafya konularının öğretimi. Yüksek Lisans Tezi, Sosyal Bilimler Enstitüsü Atatürk Üniversitesi, Erzurum.

Denzin, N. K. \& Lincoln, Y. S. (eds.). (2000). Handbook of qualitative research (2nd ed.). California, USA: Sage Publications. 
Duman, B. ve Girgin, M. (2007). Eğitim fakültesi öğrencilerinin harita okuryazarlığına ilişkin görüşleri. Doğu Coğrafya Dergisi, 12 (7), 185-202.

Erol, H. (2017). Ortaokul öğrencilerinin harita okuryazarlık becerilerine ilişkin bir değerlendirme. Ajesı, 7(3), 425-457.

Gurbetoğlu, A. (2018). Bilimsel araştırma yöntemleri. http://agurbetoglu.com/files/2\%20ara\%c5\%9etırma\%20\%20t\%c3\%9crler\%c4\%b0.pdf.

Kartal, F. (2016). Ortaöğretim ögrencilerinin harita okuryazarlık düzeylerinin çeşitli değişkenler açısından incelenmesi. Yüksek lisans tezi, Eğitim Bilimleri Enstitüsü Cumhuriyet Üniversitesi, Sivas.

Kayacan, Z. (2010). İlköğretim altıncı sınıf öğrencilerinin coğrafi koordinatlarla ilgili kavram yanılgıları. Yüksek lisans tezi, Sosyal Bilimler Enstitüsü Balıkesir Üniversitesi, Balıkesir.

Koç, H. ve Çifçi, T. (2016). Sınıf öğretmeni adaylarının harita okuryazarlık düzeylerinin çeşitli değişkenler açısından incelenmesi. Marmara Coğrafya Dergisi, 9(20), 9-20.

Kuzey, M. ve Değirmenci, Y. (2019). Sosyal bilgiler öğretmen adaylarının harita ve yön okuryazarlığına ilişkin kavramları anlama düzeyleri ve kavram yanılgıları. Milli Eğitim Dergisi, 48 (223), 207-230.

Mcclure, R. W. (1992). A conceptual model for map skills curriculum development based upon a cognitive field theory philosophy. Faculty of the graduate college of the oklahoma state university, Degree of doctor education, Oklahoma

Memişoğlu, H. ve Öner, G. (2013). Sosyal bilgiler dersinde öğrenci ve öğretmen görüşlerine göre coğrafya konularının öğretimi. Ĕgitim ve Öğretim Araştırmaları Dergisi, 2(3), 347366.

Milli Eğitim Bakanlığı (2018). Sosyal bilgiler dersi öğretim programı (ilkokul ve ortaokul 4, 5, 6 ve 7. siniflar). Ankara: Devlet Kitaplar1 Basım Evi.

Milli Eğitim Bakanlığı (2005). İlköğretim sosyal bilgiler dersi 6- 7. sınıflar öğretim programı ve kılavuzu (taslak basım). Ankara: Devlet Kitapları Basım Evi.

Nas, R. (2000). Hayat bilgisi ve sosyal bilgiler öğretimi. Bursa: Ezgi Kitabevi.

Özgen, N. (2010). Fiziki coğrafya dersi öğretim metoduna farklı bir yaklaşım: gezi- gözlem destekli öğretim. Marmara Coğrafya Dergisi, 23, 373-388.

Öztürk, Ş. (2005). Anket geliştirme. Türk Eğitim Bilimleri Dergisi, 3 (2), 133-151.

Pekdemir, Ü. ve Polat, S. (2016). Sosyal bilgiler 5. ve 6. sınıf ders kitaplarında harita kullanımı. Ekev Akademi Dergisi, 20 (68), 363-382. 
YYÜ Eğitim Fakültesi Dergisi (YYU Journal of Education Faculty), 2021;18(2)712-733,http://efdergi.yyu.edu.tr,

Sönmez, Ö. F. ve Aksoy, B. (2012). İlköğretim ikinci kademe öğrencilerinin harita beceri düzeylerinin belirlenmesi. Turkish Studies, 7(1) , 1905-1924.

Üzümcü, O. N. (2007). İlköğretim 6. sınıf sosyal bilgiler dersinde harita okuma becerisinin aktif ögrenme yöntemiyle kazandırılması. Yüksek lisans tezi, Gazi Üniversitesi Eğitim Bilimleri, Ankara.

Ünlü, M., Üçışık S. ve Özey R. (2002). Coğrafya eğitim ve öğretiminde haritaların önemi. Marmara Coğrafya Dergisi, 5, 9-25.

Yazıc1, H. ve Samanc1, O. (2003). İlköğretim öğrencilerinin sosyal bilgiler ders konuları ile ilgili bazı kavramları anlama düzeyleri. Milli Eğitim Dergisi, 158, 2-6 http://dhgm.meb.gov.tr/yayimlar/dergiler/milli_egitim_dergisi/158/yazici.htm.

Yıldırım, A., ve Şimşek, H. (2016). Sosyal bilimlerde nitel araştırma yöntemleri (10. baskı). Anlara: Seçkin Yayıncılık.

Yıldız, S. (2017). Sosyal bilimlerde örnekleme sorunu: Nicel ve nitel paradigmalardan örnekleme kuramına bütüncül bir bakış. Kesit Akademi Dergisi, 3(11), 421-442.

Yılmaz, C. (1997). Coğrafya eğitiminde arazi tatbikatlarının önemi ve bir uygulama örneği. Area, 10 (1), 287-307. 


\section{Summary}

\section{Statement of Problem}

The spatial relationship, which begins with the birth of human beings and increases with the fulfillment of various needs, begins to become multidimensional with the school life. In this process, the individual begins to get to know the place where she/he lives in multidimensionally and to learn important geographic information more systematically, especially through the Social Studies Course. In the Social Studies Curriculum, map literacy skills are included in the learning area called People, Places and Environments, which is directly related to the discipline of geography. Map literacy is an essential communication tool necessary to interpret complex information displayed visually through maps, a competence that cannot be ignored in the development of geographers (Burton \& Pitt, 1993). The aim of the study is to reveal the competences of 8th grade middle school students, who took the social studies course in four years, on map literacy skills

\section{Method}

This study is a descriptive study which is one of the quantitative research models. In descriptive model studies that are most widely used in education, the current situation of a subject is investigated and tried to be revealed (Gurbetoğlu, 2018). In this study, the map literacy skills of middle school 8th grade students who took the social studies course for four semesters were tried to be evaluated.

\section{Findings}

When Table 2 is examined, It is seen that the students gave information about the function of the map rather than the scientific explanation of the map concept. Students especially mentioned that the map is used in finding location and direction.

When Table 3 is examined the majority of the students emphasized scale and bird's eye view of the mapping criteria. But $26 \%$ of the students stated that they do not know the criteria that should be included in the map drawing.

When Table 4 is examined, It is seen that $15.5 \%$ of the students do not know the map types. The majority of the students sorted the usage of the maps as "Turkey's political map", "Turkey physical map", "Turkey geographical map", "Turkey map", "world map", "Turkey's population map". It was determined that the students did not have information about map types according to their scales. 
When Table 5 is examined, It is seen that $24.4 \%$ of the students do not know the colors used in the maps. Most of the students correlated the mountainous and high parts with brown, the sea and water regions with the color blue, and the low and forest areas with the green color.

When Table 6 is examined, It is seen that $51.1 \%$ of the students did not know what the signs used on the map mean, $48.8 \%$ knew certain signs (airline, railway, coordinate, capital, province, lake, port, dam, country border), 22\% called these signs as legends.

When Table 7 is examined, It is seen that $41.1 \%$ of the students do not know the concept of earth. $21.1 \%$ of the students stated the earth as "mountains, plains, seas", $10 \%$ as "deep, shallow, hump and round", $8.8 \%$ as "physical characteristics of the place we live in", $7.7 \%$ as the crust of the earth" and 5.5\% as "the land and seas in the world".

When Table 8 is examined, It is seen that $20 \%$ of the students do not know the imaginary lines that are used to determine the position. $44.4 \%$ of the students stated these imaginary lines as "meridian", $41.1 \%$ as "longitude", $36.6 \%$ as "latitude", $31.1 \%$ as "parallel", $12.2 \%$ as “equator”, $6.6 \%$ as “coordinate” and $4.4 \%$ as “axis”.

When Table 9 is examined, It is seen that \%35.5 of the students do not know the coordinates of Turkey. It was determined that $33.3 \%$ of the students confused these coordinates.

When Table 10 is examined, It were asked from students to identify the intersection of the 40 north parallel and 42 east meridians on the map provided. It is seen that $32.2 \%$ of the students do not know how to locate with the given coordinate, $44.4 \%$ of them make correct determination (Erzurum), and $21.1 \%$ of them make wrong determination.

\section{Discussion and Conclusion}

When the obtained findings are examined; It is seen that the students do not have detailed information about what the concept of map is, and they explain this concept mostly by considering the functionality dimension. One of the important disciplines within the social studies course, which has been created with an interdisciplinary approach, is geography. In the learning area named People, Places and Environments, the subject of maps, which forms the basis of the discipline of geography, has been mentioned. Field trips and applied mapping activities are important for the effective teaching of the subjects related to the discipline of geography consisting of many facts and concepts. In the other finding, the competencies of the students regarding what the criteria should be found in map drawings were examined. It was concluded that $1 / 3$ of the students did not know what these criteria were, and the remaining students expressed the criteria (such as scale, bird's eye view, coordinate) used in map drawing 
incompletely. The fact that the conceptual explanation of the map is known by the students means that the criteria for drawing a map are also known. As in many lessons, it is important to transfer practical knowledge in life rather than unnecessary details in the Social Studies course. Buğdaycı and Bildirici (2009) stated that the general purpose of teaching is to provide students with enough key information, but to teach the ways and means of providing and using information when and where it is necessary. In another finding sudents' opinions about map types were examined. It was concluded that students sorted the maps acoording to the general purpose as Turkey's political map, physical map of Turkey, Turkey geographical map, Turkey map, world map. However, they did not have any information about map types according to their scales. As mentioned above, maps constitute the basis of geography teaching. What exactly these materials, which are used most in the lessons, mean, and their types should be taught to the students with application activities. Pekdemir and Polat (2016) stated that maps are an important supplementary course material in Social Studies course.

In the other finding, it was tried to determine what the students knew about the colors used in the maps. It was concluded that approximately $1 / 4$ of the students did not know what the colors used in the map mean, and the rest correlated the brown with height or mountainous area, blue with water or sea, and green with forest area. Instead of having students memorize colors, creating maps and map interpretation activities will provide permanent learning. Another finding was to determine what the students knew about the signs used in the map. It was concluded that most of the students participating in the study did not know what the symbols on the map meant as legends. The fact that 8th grade students do not know the symbols used in the map will negatively affect their map interpretation skills. Mcclure (1992) stated that mapping skill is primarily the ability to understand and interpret symbols. In another finding, it was determined that most of the students do not know the concept of earth. This result reveals the importance of field and field applications in the teaching of geographical concepts. Effective use of maps in teaching the concept of earth will minimize the negative effects of rote learning. In another finding, the students' information about determining the geographical location of a place on the map was tried to be determined. In this result, a confusion of information was detected in the students. Students confused the concepts of latitude and longitude with the concepts of "parallel and meridian". In another finding the students' competency about the coordinates of Turkey was tried to determined. Serious difficulties are generally encountered in teaching abstract subjects and concepts of the discipline of geography. Memişoğlu and Öner (2013) stated in their study that students have difficulties in understanding issues related to 
YYÜ Eğitim Fakültesi Dergisi (YYU Journal of Education Faculty), 2021;18(2)712-733,http://efdergi.yyu.edu.tr,

coordinates, the shape and movements of the world. When the last finding is examined, it is seen that the students are insufficient in determining a place whose coordinates are given on the map. Locating in a given coordinate is one of the important map reading skills. These skills can be internalized and fully understood by students with an applied geography education in which the student is at the center. 